\title{
Presentation and Delivery of Tumor Necrosis Factor-Related Apoptosis-Inducing Ligand via Elongated Plant Viral Nanoparticle Enhances Antitumor Efficacy
}

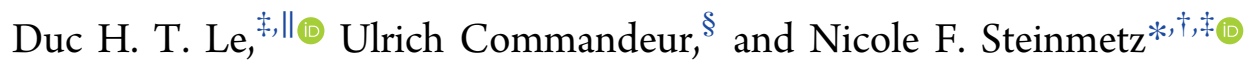
${ }^{\dagger}$ Department of NanoEngineering, Moores Cancer Center, Department of Radiology, Department of Bioengineering, University of California, San Diego, La Jolla, California 92093, United States
${ }^{\ddagger}$ Department of Biomedical Engineering, Case Western Reserve University School of Medicine, Cleveland, Ohio 44106, United States
${ }^{\S}$ Department of Molecular Biology, RWTH-Aachen University, Aachen 52064, Germany

Supporting Information

ABSTRACT: Potato virus $\mathrm{X}$ (PVX) is a flexuous plant virus-based nanotechnology with promise in cancer therapy. As a high aspect ratio biologic $(13 \times 515 \mathrm{~nm})$, PVX has excellent spatial control in structures and functions, offering high-precision nanoengineering for multivalent display of functional moieties. Herein, we demonstrate the preparation of the PVX-based nanocarrier for delivery of tumor necrosis factor-related apoptosis-inducing ligand (TRAIL), a promising protein drug that induces apoptosis in cancer cells but not healthy cells. TRAIL bound to PVX by coordination bonds between nickel-coordinated nitrilotriacetic acid on PVX and His-tag on the protein could mimic the bioactive "membrane-bound" state in native TRAIL, resulting in an

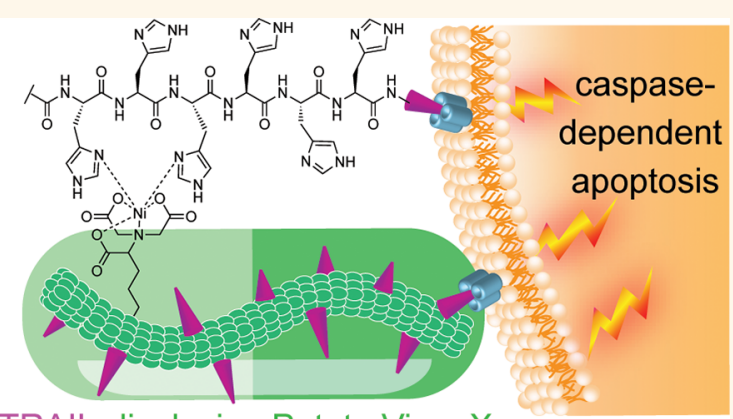

TRAIL-displaying Potato Virus X elongated nanoparticle displaying up 490 therapeutic protein molecules. Our data show that PVX-delivered TRAIL activates caspase-mediated apoptosis more efficiently compared to soluble TRAIL; also in vivo the therapeutic nanoparticle outperforms in delaying tumor growth in an athymic nude mouse model bearing human triple-negative breast cancer xenografts. This proof-of-concept work highlights the potential of filamentous plant virus nanotechnologies, particularly for targeting protein drug delivery for cancer therapy.

KEYWORDS: plant viral nanoparticle, potato virus $X$, tumor necrosis factor-related apoptosis-inducing ligand, death receptor, drug delivery, nanomedicine, anticancer therapy

r he ultimate goal toward effective anticancer therapy is to develop therapeutics that specifically elicit apoptosis in cancer cells while sparing non-malignant cells. Tumor necrosis factor (TNF)-related apoptosis-inducing ligand (TRAIL) has been identified as one of the promising candidate therapeutics. TRAIL is an innate immune cytokine broadly expressed by activated immune cells responsible for suppressing tumor initiation and metastasis. ${ }^{1,2}$ The protein specifically binds to death receptors, namely DR4 and DR5, which are overexpressed in many cancer cells but not healthy cells. TRAIL-DR4/5 interactions launch a signaling cascade triggering a caspase-dependent apoptosis process. ${ }^{3,4}$ Similar to most TNF-ligands, TRAIL is expressed as a homotrimeric type II transmembrane protein or converted into a soluble form upon proteolytic cleavage. It should be noted that membranebound TRAIL induces stronger receptor oligomerization and thus activates apoptosis more efficiently than its soluble counterpart. ${ }^{5,6}$ Since its discovery, TRAIL has been widely developed and tested as a therapeutic protein in oncology with promising results in various preclinical models. ${ }^{7}$ However, clinical trials with soluble TRAIL were rather disappointing: While TRAIL therapy demonstrated safety, lack of efficacy was attributed to the fact that soluble TRAIL has poor physicochemical properties and does not effectively trigger apoptosis in cancer cells. ${ }^{8-10}$ Therefore, there is a need for the rational design and development of delivery platforms to present multivalent TRAIL in a surface-bound state.

Received: December 14, 2018

Accepted: January 10, 2019

Published: January 22, 2019 
Advances in nanotechnology and drug delivery have provided myriad rational designs of nanoparticles (NPs) varied in sizes, shapes, compositions, or surface chemistries to meet the need for safe and effective delivery of TRAIL. ${ }^{11-13}$ Examples of TRAIL delivery systems include liposomes, ${ }^{14}$ polymer-based, ${ }^{15}$ protein-based, ${ }^{16}$ or inorganic NPs. ${ }^{17}$ In most of the cases, the therapeutic proteins were chemically conjugated onto the NP surface via designated cysteine or $\mathrm{N}$-terminal lysine, ${ }^{18}$ to display immobilized TRAIL mimicking the membrane-bound state. As with many drug delivery approaches, efforts in designing and developing TRAIL delivery systems have been focused on the use of spherical NPs, but this may not be optimal. Recently, a growing body of data from the studies on the shape effects of NPs in microfluidic models and animal models indicates that a paradigm shift is needed and that anisotropic nanomaterials with high aspect ratios (length/width) $>5$ may be more suitable for drug delivery. ${ }^{19-21}$ High aspect ratio, elongated NPs are less recognized and taken up by phagocytic cells and have enhanced margination, extravasation, and tissue penetration in comparison to the isotropic counterparts. ${ }^{20}$ Furthermore, nanorods or filaments exhibit a larger contact surface area, permitting more efficient display and cross-linking between functional modules and targeted receptors, as compared to spherical nanomaterials that may not achieve multivalent interactions with the target cell/receptor due to their high curvature. ${ }^{20}$

While there are considerable designs of spherical nanocarriers, fewer options are present when it comes to anisotropic NPs. It remains challenging to precisely control the synthesis of high aspect ratio materials with excellent monodispersity using synthetic approaches. Carbon nanotubes (CNTs) and filomicelles are among a few synthetic materials that have been prepared and explored as drug delivery carriers. ${ }^{22,23}$ Nanovectorization of TRAIL with single-walled CNTs is the only example of using high aspect ratio nanostructures; the TRAIL nanovector exhibited enhanced cell killing effects in vitro. ${ }^{24}$ Interestingly, conjugated TRAIL, even in its monomeric form, can also induce clustering of death receptors and efficient activated apoptosis compared to soluble TRAIL, implying the advantages of NP-bound TRAIL. While the structures and functionalization of CNTs are well-controlled, there are still controversies regarding toxicity, and thus there is a need to further explore other options for engineering guidelines of rodshaped NPs and also to provide suitable materials in clinics. Here, we turned toward nature's nanocarriers and are repurposing the rod-shaped and filamentous plant viruses for drug delivery applications. ${ }^{25-27}$ One of the promising candidates is potato virus $\mathrm{X}$ ( $\mathrm{PVX})$, a plant virus belonging to the Potexvirus group. The virion is assembled from 1270 identical $25 \mathrm{kDa}$ coat protein (CP) units orderly arranged around its single-stranded RNA; the assembled construct results in a flexuous elongated NP measuring $515 \mathrm{~nm}$ in length and $13 \mathrm{~nm}$ in diameter. Via mechanical inoculation and extraction from Nicotiana benthamiana leaves, $\sim 20 \mathrm{mg}$ of PVX is typically obtained from $100 \mathrm{~g}$ of infected leaf material; the biomanufacturing can be scaled up via farming. Being a biologic nanotechnology, PVX particles are obtained with a high degree of reproducibility and monodispersity. ${ }^{28}$ These characteristics are important factors for quality control and assurance ( $\mathrm{QC} / \mathrm{QA})$, especially when entering the translational pathway. The proteinaceous scaffold from PVX is biocompatible, biodegradable, and non-infectious to mammal cells, adding a layer of biosafety. PVX was shown to be biosafe with no apparent effects on human erythrocytes in vitro and neither toxic nor teratogenic in warm-blooded animals. ${ }^{29}$ Regarding its engineerability, the viral NP, with multiple surface-exposed residues such as lysine and cysteine, can be readily modified to load not only single but multiple modules such as peptide ligands or epitopes as well as fluorescent probes and MRI contrast agents. ${ }^{30-32}$ PVX displaying targeting ligands is stable in serum and thus is applicable for in vivo studies. $^{33}$ Besides bioconjugation to display functional modules, hydrophobic drugs such as doxorubicin can also be loaded into grooves of the protein assembly via hydrophobic interactions. $^{27}$ In agreement with observations in synthetic anisotropic systems, ${ }^{20}$ PVX was demonstrated to have enhanced tumor homing compared to its spherical viral counterpart, cowpea mosaic virus. ${ }^{29}$ Together, the engineerability and structural properties make PVX an intriguing nanoplatform technology, and it has been investigated for biomedical applications such as drug delivery, ${ }^{29}$ bioimaging, $^{30,34}$ and immunotherapies. ${ }^{31,32}$

Here, we report the development of the flexuous, filamentous PVX for presenting and delivering "membranebound" TRAIL. To develop therapeutic TRAIL-loaded PVX, we utilized noncovalent conjugation based on the coordination bonds between nickel-coordinated nitrilotriacetic acid (NiNTA) modules displayed on PVX surface and TRAIL with an N-terminal His-tag (Figure 1). This method offers several

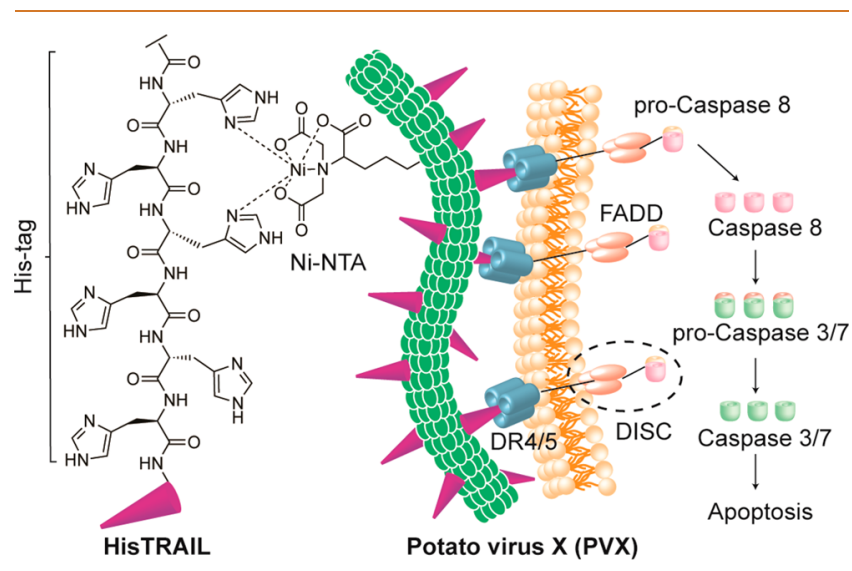

Figure 1. Preparation of the therapeutic conjugate, PVXHisTRAIL via the coordination bond between a Ni-NTA group on PVX (Ni-NTA was conjugated to PVX via $\mathrm{N}$-hydroxysuccinimide (NHS) chemistry targeting solvent-exposed lysine side chains) and a His-tag at the N-terminus of HisTRAIL (purple triangle). Multivalent display of HisTRAIL on the elongated PVX particle allows efficient binding on death receptors DR4/5 (blue trimers) to activate the caspase-dependent apoptosis in cancer cells.

advantages $v s$ traditional bioconjugation strategies: (1) PVX with multiple surface-exposed lysines can be targeted to display up to 1000-1500 small chemical modifiers (here Ni-NTA) per particle; ${ }^{30,35}$ the conjugation of high molecular weight molecules such as proteins or enzymes to viral NP systems generally yields lower conjugation efficiencies. ${ }^{36,37}$ (2) As most recombinant proteins expressed from bacterial systems typically incorporate a His-tag for purification either at the $\mathrm{N}$ - or C-terminus, no post-harvest/purification modification is required for TRAIL conjugation, thus reducing the manufacturing steps, heterogeneity in chemical conjugation, and also 
A

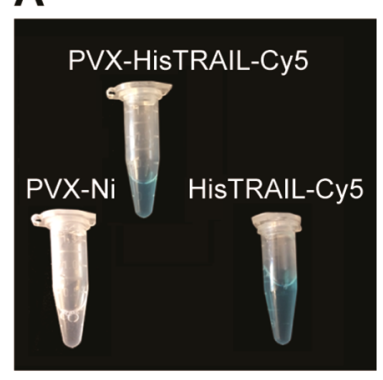

B

PVX-Ni

PVXHisTRAIL-

Cy5

HisTRAIL-

Cy5
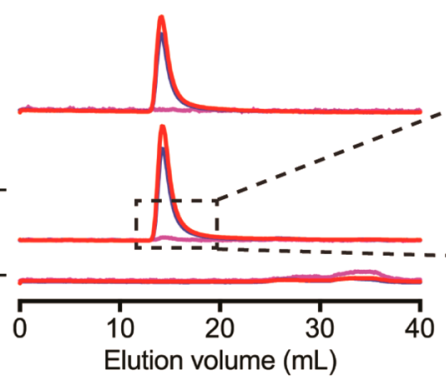

volume $(\mathrm{mL})$
$-280 \mathrm{~nm}$

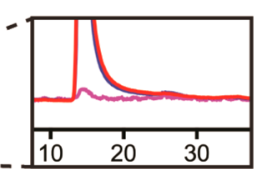

0

$647 \mathrm{~nm}$
C

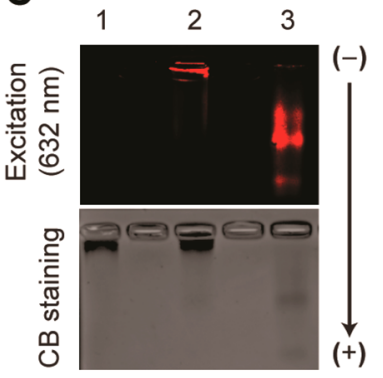

D

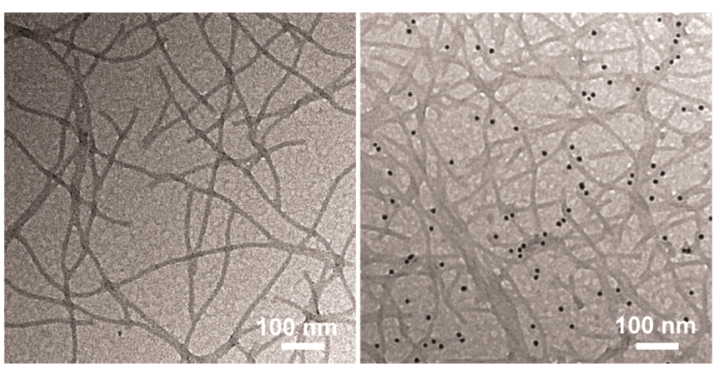

E

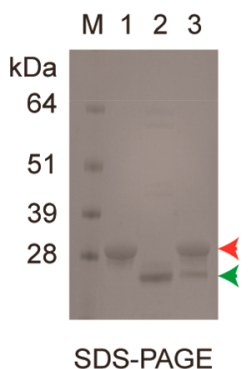

anti-PVX
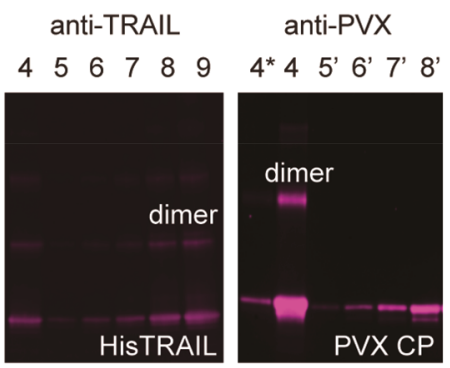

Fluorescent western blot

Figure 2. (A-C) Characterization of PVX-HisTRAIL-Cy5. (A) As-prepared PVX-Ni suspension (transparent), PVX-HisTRAIL-Cy5 suspension (blue), and TRAIL-Cy5 solution (blue). (B) SEC profiles of the corresponding PVX-based NP preparations. The inset shows coelution of HisTRAIL-Cy5 (absorbance $647 \mathrm{~nm}$ ) with PVX (absorbance $260 \mathrm{~nm}, 280 \mathrm{~nm}$ ). (C) Agarose gel electrophoresis of (1) PVX-Ni, (2) PVX-HisTRAIL-Cy5, and (3) HisTRAIL-Cy5. The samples were visualized upon fluorescent excitation at $632 \mathrm{~nm}$ (red) and after Coomassie blue (CB) staining under white light. (D) TEM images of negatively stained PVX-Ni (left) vs PVX-HisTRAIL-biotin (right), after being treated with antibiotin antibodies conjugated with gold NPs. (E) Quantitative analysis of PVX-HisTRAIL by SDS-PAGE and Western blot. In SDS-PAGE, (1) PVX-Ni, (2) HisTRAIL, and (3) PVX-HisTRAIL in the presence of DTT were run in 4-12\% NuPAGE gel in $1 \times$ MOPS running buffer. Separated PVX CP and HisTRAIL were indicated by the red and green arrows, respectively. To determine PVX and HisTRAIL amounts by Western blot (stained with either anti-TRAIL or anti-PVX antibodies), the PVX-HisTRAIL conjugate was loaded at either original concentration (4) or $10 \times$ dilution $(4 *)$ so that protein amounts lie within linear range of standard curves. For standard curves, HisTRAIL was loaded at $0.25,0.5,1,2.5$, and $5 \mu \mathrm{g}(5-9)$, and PVX was loaded at $0.1,0.25,0.5,1 \mu \mathrm{g}\left(5^{\prime}-9^{\prime}\right)$. Fluorescence intensities were read from FluoroChem instrument.

avoiding disruption of native structures. (3) The conjugation step is simple and achieved by mixing the Ni-NTA-displayed nanostructure (here PVX) and His-tagged protein of interest (here TRAIL) in buffer solutions, $\mathrm{pH}$ 7.4. (4) With the specific binding of TRAIL to PVX via its designated N-terminal Histag, orientational control is provided, allowing for the bioactive TRAIL at the C-terminus to be solvent-exposed upon NP display, therefore mimicking its membrane-bound state when in contact with surface-overexpressed DR4/5 receptors on cancer cells. ${ }^{18,38}$ For confirming and characterizing the therapeutic conjugate, size exclusion chromatography (SEC), gel electrophoresis, transmission electron microscopy (TEM), and quantitative Western blots (WB) were carried out. The treatment efficacies of the therapeutic NPs were evaluated in vitro in a panel of triple-negative breast cancer (TNBC) cell lines, an aggressive breast cancer subtype whose treatment options are limited in chemotherapies. Finally, the in vivo evaluation was assessed to investigate whether TRAIL-loaded PVX outperforms TRAIL alone in an athymic nude mouse model bearing MDA-MB-231 TNBC tumors.

\section{RESULTS}

Preparation and Characterization of TRAIL-Loaded PVX Nanoparticles. We have developed a protocol to construct the plant viral NP-therapeutic protein complex utilizing the coordination bond between the His-tagged protein and the Ni-NTA chelate conjugated on PVX surface.
The scheme and detailed conjugation steps are described in Supporting Information (Figures S1 and S2). Briefly, PVX was first conjugated at its solvent-exposed lysine residues to display nitrilotriacetic acid (PVX-NTA) using our established $\mathrm{Cu}(\mathrm{I})$ catalyzed azide-alkyne cycloaddition (CuCAAC) reaction ("click" chemistry) protocol. ${ }^{28}$ Free reagents after the reaction such as $\mathrm{Cu}$ ions and EDTA were removed by dialysis. Subsequently, $\mathrm{Ni}^{2+}$ ions were introduced to PVX-NTA suspension via dialysis in PBS containing $1 \mathrm{mM} \mathrm{Ni}^{2+}$ to obtain PVX displaying Ni-NTA, hereafter PVX-Ni. The presence of Ni-NTA conjugated on the viral NP was qualitatively confirmed by adding 1,4-dithiothreitol (DTT) $100 \mathrm{mM}$ final concentration; the reducing reagent converted the solution from transparent into yellow, brownish color, indicating the reduction of $\mathrm{Ni}^{2+}$ ions (Figure S2).

The therapeutic protein, hereafter denoted as HisTRAIL, contains the amino acid (aa) 114-281 sequence of human TRAIL, the region responsible for TRAIL bioactivity, ${ }^{36}$ a designated N-terminal His-tag, and a thrombin cleavage sequence allowing for removal of the His-tag if desired (Figure S3A). HisTRAIL was expressed in ClearColi BL21(DE)3 and purified using metal affinity chromatography under native condition. The purified protein was characterized by gel electrophoresis and WB (Figure S3B). It should be noted that in recombinant TRAIL expression, dimers formed via intermolecular disulfide bridge between Cys 230 typically coexist with TRAIL monomers, while unpaired Cys 230 is 
essential for bioactive TRAIL trimer formation and TRAIL/ receptor interactions. ${ }^{36}$ Therefore, purified HisTRAIL was treated by $10 \mathrm{mM}$ DTT for $1 \mathrm{~h}$ at room temperature and followed by dialysis in PBS, $\mathrm{pH}$ 7.4, to remove excess DTT and to favor HisTRAIL trimer formation; the latter was confirmed by SDS-PAGE (Figure S3C). However, it should be noted that while trimers were formed, a heterogeneous mixture of multimeric HisTRAIL is expected, as typically seen in Histagged TRAIL. ${ }^{39,40}$ After obtaining PVX-Ni and HisTRAIL separately, the two components were mixed in PBS at room temperature to allow binding of HisTRAIL onto Ni-NTA on PVX. The reaction mix was purified by ultracentrifugation to remove unbound substances such as HisTRAIL and free $\mathrm{Ni}^{2+}$ ions if there are. The pellet was resuspended in PBS, $\mathrm{pH} 7.4$ overnight to obtain the PVX-HisTRAIL suspension.

To visualize the presentation of HisTRAIL on PVX, we utilized a Cy5-labeled HisTRAIL, referred as HisTRAIL-Cy5 (Figure S4); the resulting conjugate is referred to as PVXHisTRAIL-Cy5. After purification, the obtained conjugate suspension exhibits a blue color derived from the present of Cy5 (Figure 2A). SEC was conducted to confirm the intact filamentous structure in PVX-Ni as well as PVX-HisTRAILCy5 after complexation and purification (Figure 2B). The PVX-based nanostructures eluted from the Superose- 6 column at $14.5 \mathrm{~mL}$, thus matching the elution profile of native PVX (Figure S5; it should be noted that the molecular weights of the PVX-based macromolecules are too large to resolve differences between native and modified PVX particles using this method). PVX-HisTRAIL-Cy5 absorbed light at $647 \mathrm{~nm}$ at the elution peak of the particle (Figure 2B inset), indicating the attachment of HisTRAIL-Cy5. Free HisTRAIL-Cy5 eluted at $25-39 \mathrm{~mL}$; for the PVX-HisTRAIL-Cy5 samples, no peaks were detectable at this elution volume, indicating a purified PVX-HisTRAIL preparation without presence of free HisTRAIL-Cy5. Noteworthy, fluorescently labeled HisTRAILCy5 was prepared at a 1:1 (HisTRAIL:Cy5) molar ratio: As a result, only 1 in every 4-5 HisTRAIL molecules were labeled (Figure S4). The corresponding absorbance in the SEC profile of PVX-HisTRAIL-Cy5 should only be considered as an indicator of HisTRAIL binding on PVX-Ni. The absorbance ratios of 260/280 $\mathrm{nm}$ were determined as 1.22 and 1.19 for PVX-Ni and PVX- HisTRAIL-Cy5, respectively. The shift toward the $280 \mathrm{~nm}$ absorbance (the $280 \mathrm{~nm}$ peak is indicative of proteins, while $260 \mathrm{~nm}$ is a measure for RNA contents), resulting in a decreased ratio for the PVX-HisTRAIL-Cy5 formulation, is another indicator of HisTRAIL-Cy5 loading.

Native gel electrophoresis (Figure 2C) was in agreement with SEC, also indicating successful complexation of HisTRAIL-Cy5 with PVX: Free HisTRAIL-Cy5 shows mobility toward the anode, while PVX particle being a large macromolecule does show a small degree of migration toward the anode, but the majority of the samples remain in the pockets of the gel. Co-localization of the fluorescent HisTRAIL-Cy5, detected either by excitation at $632 \mathrm{~nm}$ (red) light source or after Coomassie Blue (CB) staining and visualization under white light, with PVX, detected after $\mathrm{CB}$ staining under white light, is indicative of successful HisTRAIL-Cy5-to-PVX loading. Again, free HisTRAIL-Cy5 was not apparent in this method.

Lastly, to confirm the structural integrity of TRAILdisplaying PVX filaments, we made use of an immunogoldlabeling protocol: Similar to PVX-HisTRAIL-Cy5 preparation, HisTRAIL was first biotinylated using biotin $N$-hydroxysucci- nimide ester to provide a tag for immune staining (Figure S6). PVX-HisTRAIL-biotin prepared by the described method was loaded onto the TEM grid and fixed by $2.5 \%(\mathrm{v} / \mathrm{v})$ glutaraldehyde in $10 \mathrm{~min}$. Bound HisTRAIL was detected indirectly via the labeled biotin recognized by antibiotin antibodies conjugated on $10 \mathrm{~nm}$ gold NPs. PVX-Ni was also prepared using the same method as a control. The typical filamentous structures imaged by TEM confirm structural integrity for both, PVX-Ni and PVX-HisTRAIL-biotin samples (Figure 2D). PVX-bound gold NPs were observed in the case of PVX-HisTRAIL-biotin, demonstrating the multivalent display of HisTRAIL on the PVX nanoplatform technology (Figure 2D). It should be noted that due to the low labeling degree of biotin (i.e., based on Cy5-labeling experiments, we expect only a fraction of the HisTRAIL proteins to be labeled with biotin), the amount of bound gold NPs does not provide quantitative insights into the degree of labeling of PVX with HisTRAIL.

The combination of methods utilizing Cy5- and biotintagged TRAIL described above provides confidence in the HisTRAIL conjugation and display method. Next, we developed the therapeutic PVX-HisTRAIL conjugate (free of fluorescent or biotin tags). After ultracentrifugal purification, FPLC was conducted to ensure no free HisTRAIL in the PVXHisTRAIL suspension (Figure S7). Decrease in the 260/280 ratio is a sign of HisTRAIL bound to PVX. Various conditions including buffers, PVX-Ni:HisTRAIL ratios, and reaction time were optimized to achieve the highest yield of HisTRAIL on PVX. Validation of complexation of the nonchemically modified HisTRAIL to PVX was confirmed and quantified by SDS-PAGE and WB (Figure 2E). PVX-Ni, His-TRAIL, and PVX-HisTRAIL were separated on a $4-12 \%$ NuPAGE gel. DTT was added to the sample mixtures to reduce nickel and possible disulfide bonds and to separate bound HisTRAIL from PVX CP. As a result, the corresponding individual bands of the PVX CP $(25 \mathrm{kDa})$ and HisTRAIL $(22 \mathrm{kDa})$ were observed after CB staining. Analysis of SDS-PAGE data using band analysis tool and ImageJ software indicated a $32 \%$ weight ratio of HisTRAIL to PVX CP. These data were further validated by WB using rabbit anti-PVX and rabbit anti-TRAIL primary antibodies, respectively, followed by staining with antirabbit secondary antibodies conjugated with IRDye $800 \mathrm{CW}$ $(774 / 789 \mathrm{~nm})$. Data were in good agreement with SDS-PAGE and indicated $2.45 \mu \mathrm{g}$ HisTRAIL per $7.93 \mu \mathrm{g}$ PVX CP, that is, a protein weight ratio of $30.8 \%$.

Using the known molecular weights of HisTRAIL (22 kDa) and a PVX particle $\left(36 \times 10^{5} \mathrm{kDa}\right), \sim 490$ HisTRAIL molecules were attached on a PVX particle (1270 CP units), which equals $\sim 38 \%$ PVX CPs conjugated with a HisTRAIL molecule. Considering 900 molecules per particle were added into the mixture, the yield of the conjugation was $>50 \%$, attesting to the effectiveness of the noncovalent display strategy.

In Vitro Cytotoxicity Assays of PVX-HisTRAIL vs HisTRAIL. We then set out to evaluate the anticancer efficacy of the PVX-HisTRAIL therapeutic NP in parallel with HisTRAIL, determined by MTT cytotoxicity assay. Herein, a panel of TNBC cell lines, MDA-MB-231, HCC-38, and BT549 , was used. Increasing concentrations of HisTRAIL or the PVX-HisTRAIL conjugate at the corresponding HisTRAIL concentrations were incubated with cells for $12 \mathrm{~h}$ to trigger apoptosis. A representative data set of the concentrationdependent effect of HisTRAIL vs PVX-HisTRAIL on MDA- 
MB-231 cell viability is shown in Figure 3A. Both HisTRAIL and PVX-HisTRAIL exhibit cytotoxic bioactivity with PVX-

\section{A}
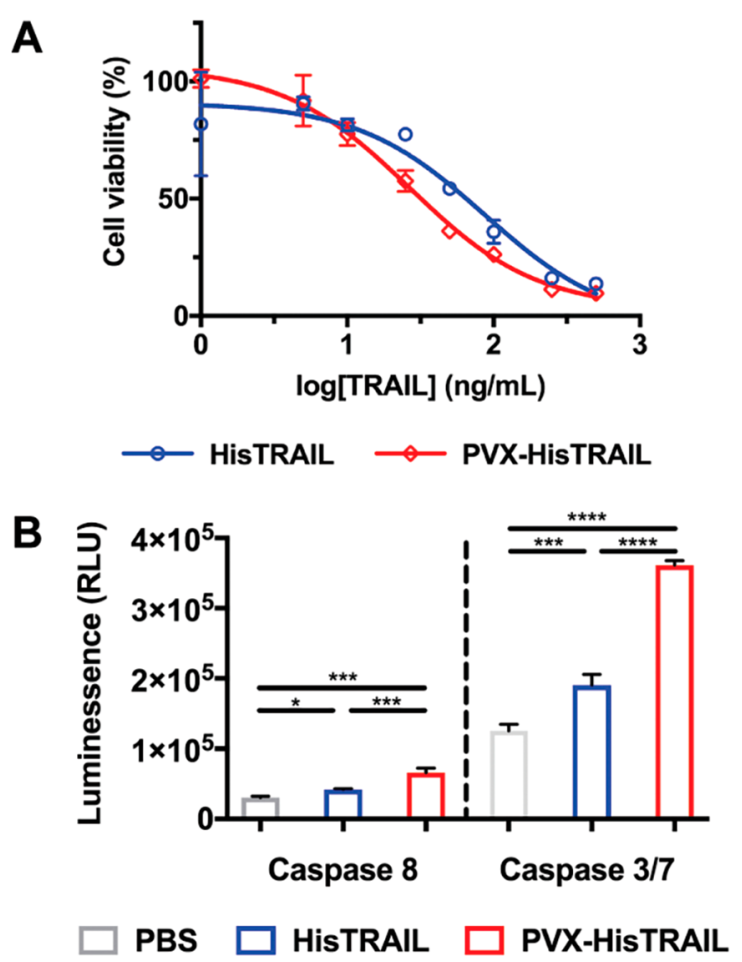

Figure 3. (A) Cell viability assays of HisTRAIL vs PVX-HisTRAIL determined using the MDA-MB-231 TNBC cell line model. (B) Levels of activated caspase- 8 and caspase- $3 / 7$ after $3 \mathrm{~h}$ treatment

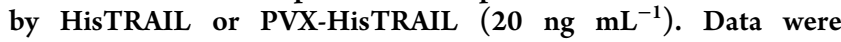
expressed as means \pm SD. Error bars shorter than the marker sizes were not shown by GraphPad Prism software. Statistical analysis was determined based on one-way ANOVA test calculated by GraphPad Prism, * $p<0.05, * * * p<0.001, * * * * p<0.0001$.

HisTRAIL outperforming free HisTRAIL. The $\mathrm{IC}_{50}$ value for HisTRAIL on the PVX conjugate was determined at $26.7 \mathrm{ng}$ $\mathrm{mL}^{-1}$, which is 3.25 -fold lower than the $\mathrm{IC}_{50}$ value for HisTRAIL (86.6 $\mathrm{ng} \mathrm{mL}^{-1}$ ). PVX-Ni did not exhibit cell toxicity at the highest corresponding concentration in PVXHisTRAIL, confirming the biocompatibility of the delivery platform. An even more profound effect was observed in other TNBC cell lines (Table 1), with 9.9-fold and 9.3-fold lower in

Table 1. IC $_{50}$ Values $\left(\mathrm{ng} \mathrm{mL}^{-1}\right)$ of HisTRAIL $v s$ PVXHisTRAIL in Various TNBC Models, Determined by GraphPad Prism Software

\begin{tabular}{lccc} 
& MDA-MB-231 & HCC-38 & BT-549 \\
HisTRAIL & 86.8 & 367.2 & 543.0 \\
PVX-HisTRAIL & 26.7 & 36.8 & 58.0 \\
\hline
\end{tabular}

$\mathrm{IC}_{50}$ values for PVX-HisTRAIL $v$ f free HisTRAIL using HCC38 and BT-549 cell lines, respectively. Neither PVX-HisTRAIL nor HisTRAIL induced apoptosis in SK-BR-3, the HER-2 amplified breast cancer cell line (Figure S8). These data are consistent with previous reports that indicate effectiveness of TRAIL therapy in TNBC, but not HER-2 positive breast cancer. ${ }^{41,42}$ Given that TNBC is an aggressive, life-threatening breast cancer subtype, whose available treatment is limited to chemotherapy, this "PVX-bound" TRAIL concept might be a promising approach for TRAIL-based therapy for future TNBC treatment.

TRAIL-DR4/5 receptor binding activates caspase-dependent apoptosis. Specifically, TRAIL-DR4/5 receptor binding induces receptor oligomerization, followed by the recruitment of FAS-associated protein with death domain (FADD) and pro-caspase- 8 to form a functional death-inducing signaling complex (DISC) at the plasma membrane. Subsequently, caspase- 8 is activated and released into the cytosol, where it cleaves and activates caspase- 3 or caspase- 7 to execute the apoptosis in cancer cells (Figure 1)..$^{5}$ Therefore, we determined differences in levels of caspase- 8 and caspase- $3 / 7$ activated after $3 \mathrm{~h}$ treated by HisTRAIL or PVX-HisTRAIL in the MDA-MB-231 model (Figure 3B). At a dose of $20 \mathrm{ng}$ $\mathrm{mL}^{-1}$ HisTRAIL, the level of caspase- 8 in PVX-HisTRAIL increased about 2 -fold compared to the PBS control, while free His-TRAIL protein only increased caspase- 8 levels by 1.38 -fold compared to PBS. The resulting caspase-3/7 showed a similar trend with a 2.9-fold increase for PVX-HisTRAIL and a 1.5fold for His-TRAIL vs PBS controls. These data are consistent with results from cell viability assays, and data indicate that surface-bound HisTRAIL displayed and delivered by PVX is more effective in that it activates caspases leading to apoptosis of TNBC cells.

In Vivo Treatment of MDA-MB-231 Tumors in the Athymic Nude Mouse Models. Based on the promising performance of PVX-HisTRAIL in vitro, we continued investigating the tumor-inhibiting effects in an athymic nude mouse model bearing an MDA-MB-231 tumor. The MDAMB-231 model was chosen because this cell line showed the highest sensitivity toward the PVX-HisTRAIL treatment (Table 1). While we envision systemic administration for clinical applications, we started here by evaluating intratumoral treatments to focus on the question as to whether PVXdelivered HisTRAIL would outperform free HisTRAIL. The intratumoral treatment allows to precisely control and match the dosing and thus eliminates confounding factors from varying biodistribution. Clinically, TRAIL is administrated intravenously at doses of $10 \mathrm{mg} \mathrm{kg}{ }^{-1}$. Assuming that $1-5 \%$ of the injected dose $(2.5-12.5 \mu \mathrm{g})$ reaches the tumor site, ${ }^{43,44}$ we chose a dose of $5 \mu \mathrm{g}$ HisTRAIL per tumor for intratumoral injections. PVX-HisTRAIL or HisTRAIL was injected intratumorally every 2 days. PBS and PVX-Ni, at the corresponding particle amount injected for PVX-HisTRAIL $(\sim 12-15 \mu \mathrm{g}$ particle per injection), were used as controls. Changes in tumor volume during treatment and distribution of individual tumor volume in each group are shown in Figures 4A,B, respectively. Both HisTRAIL and PVX-HisTRAIL demonstrate inhibiting effects with PVX-HisTRAIL outperforming free HisTRAIL. The PVX-Ni carrier has no efficacy compared to the PBS control group. At day 30 post-first treatment, average relative tumor volume increased by 5.65-fold and 5.09fold for PVX-Ni and PBS groups, respectively. In contrast, tumor volumes for the free HisTRAIL-treated group increased by 2.53 -fold, while there was essentially no increase in tumor volume for the group treated with PVX-HisTRAIL (increase was 1.09-fold vs starting volume; Figure 4A). Statistically significant difference between PVX-HisTRAIL and the controls (PBS and PVX-Ni) was apparent $(p<0.05$ based on one-way ANOVA test determined by GraphPad Prism; Figure 4B). Even though there was no significant difference between PVXHisTRAIL and HisTRAIL, we could observe a clear trend indicating more effective inhibition from the conjugate NP 
A

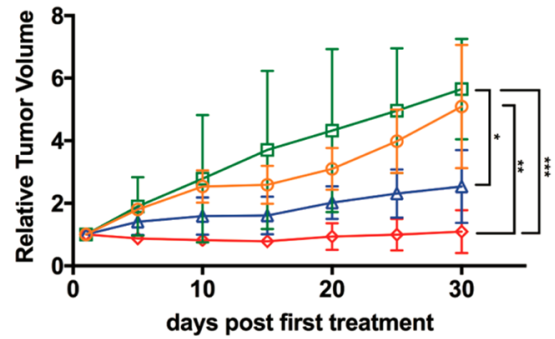

$\circ$ PBS

口 PVX-Ni

$\triangle$ HisTRAIL

$\diamond$ PVX-

HisTRAIL

B

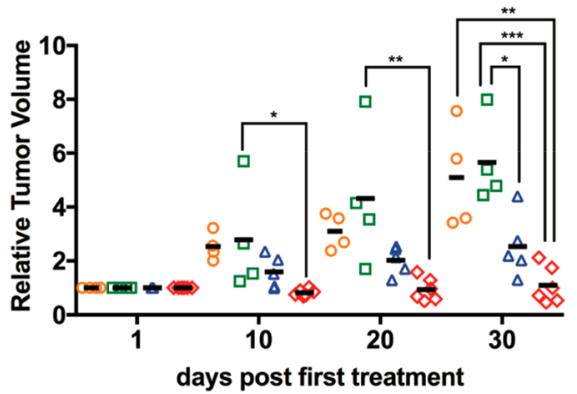

PBS $\square$ PVX-Ni $\triangle$ HisTRAIL $\diamond$ PVX-HisTRAlL

C

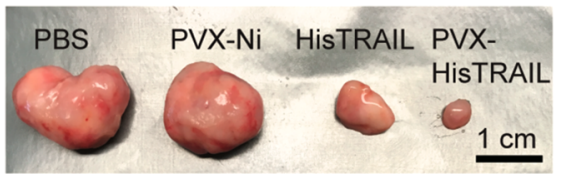

Figure 4. (A, B) Treatment of MDA-MB-231 xenografts in an athymic nude mouse model. 6-week-old female NCR nu/nu mice were injected subcutaneously into the right flank with $2 \times 10^{6}$ cells; treatment began when tumor volume reached $100-150 \mathrm{~mm}^{3}$, approximately 2 weeks after tumor cell inoculation. Mice were assigned randomly to each group: PVX-HisTRAIL: $n=6$, HisTRAIL: $n=5$, PVX-Ni: $n=4$, and PBS: $n=4$. PVX-HisTRAIL or HisTRAIL was injected intratumorally at the dose of $5 \mu \mathrm{g}$ HisTRAIL protein/injection every other day. Twenty $\mu \mathrm{L}$ PBS or corresponding particle amount of $\mathrm{PVX}-\mathrm{Ni}$ were injected as controls. Tumor volume was normalized to the volume at the initial day. Data were expressed as means \pm SD (A) Tumor growth curve during treatment. (B) Tumor volume distribution in each group during treatment. (C) Representative of isolated tumor tissues after treatment. Statistical analysis was determined based on one-way ANOVA test calculated by GraphPad Prism, * $p<$ $0.05, * * p<0.01, * * * p<0.001$.

over HisTRAIL alone; four among six mice treated by PVXHisTRAIL showed reduced tumor volumes since the first treatment, while all the mice treated by HisTRAIL showed increased tumor volumes (Figures 4A,B). Representative images of exercised tumors from each group are shown in Figure 4C, in which the smallest is dissected from a mouse treated by PVX-HisTRAIL at the end of treatment. Even though not as effective as the conjugate formulate, HisTRAIL also showed effective inhibition resulting in a smaller size compared to the controls (Figure 4C).

The potential toxicity of the in vivo treatment was accessed by monitoring changes in body weights of mice (Figure S9). No changes in body weight were observed comparing the various treatment groups, therefore indicating that the treatment was well tolerated. While nickel can be toxic, here the ions were used at low concentrations at $1-1.5 \mathrm{ppm}$. Based on previous reports, this is in the low toxicity range. ${ }^{45}$
However, the localized administration also reduces systemic exposure and likely mitigates $\mathrm{Ni}$-induced toxicities.

Together, our data indicate that the PVX-delivered TRAIL outperforms free TRAIL in a mouse model of TNBC; PVXdelivered and displayed TRAIL shows high efficacy and as such may be a promising candidate for further clinical development.

\section{DISCUSSION}

Nanotechnology delivery systems hold potential to enhance efficacy of TRAIL cancer therapy. For example, soluble TRAIL was used in combination with doxorubicin, a chemo-drug acting as a TRAIL sensitizer that upregulates TRAIL receptors DR4 and DR5. ${ }^{46}$ The dual-therapy resulted in a synergetic effect achieving better tumor control compared to either monotherapy. Recently, polymeric NPs were used as a mechano-amplifiers to enhance the TRAIL-apoptotic effects. ${ }^{47}$ Furthermore, NPs have been developed as a carrier system to deliver TRAIL and mimic the membrane-bound state of the therapeutic protein to enhance the biostability and its efficacy in vivo. ${ }^{12}$ Liposomes are probably the most exploited systems in cancer nanotechnology, and liposomal formulations of TRAIL have been reported. In one application, a TRAIL derivative with engineered $\mathrm{N}$-terminal cysteine residue was first conjugated to a maleimide-functionalized lipid molecule that was then incorporated into a PEGylated liposome, resulting in a $90 \mathrm{~nm}$ vesicle displaying up to 60 TRAIL molecules $(\sim 0.3 \%$ mol of overall lipid molecules). ${ }^{18}$ Also noncovalent modification making use of the His-tag-Ni-NTA interactions was demonstrated: His-tagged TRAIL was tethered onto Ni-NTAmodified lipidic membranes of large, unilamellar vesicle (LUV); up to 137 TRAIL molecules per $150 \mathrm{~nm}$ LUV were presented. ${ }^{48}$ Furthermore, in an effort to mimic the cytotoxic activity of natural killer cells, liposomes displaying TRAIL were further decorated with E-selectin adhesion receptor to enable the immobilization of TRAIL-NP onto leukocytes for detecting and killing circulating colon and prostate cancer cells. ${ }^{49}$ In addition to the described chemical display methods, genetic engineering principles have been applied to fuse TRAIL into the heavy chain of human ferritin, an intracellular protein that can from a spherical nanocage from 24 subunits. ${ }^{50}$ Predicted from the three-fold axis of symmetry characteristic of the protein-based nanocage, eight TRAIL molecules in the trimeric form can be displayed. The majority of TRAIL display platform technologies explored are spherical NPs. However, this may be not be optimal; a high aspect ratio filament is expected to display the therapeutic protein more efficiently to allow for multivalent interactions with the cell membrane. To this end, one example exploring single-walled CNTs (SWNT, $1 \times 600 \mathrm{~nm}$ ) for TRAIL delivery has been reported. ${ }^{24}$ Here, TRAIL was chemically conjugated with an NHS-handle derived from 1-pyrenebutanoic acid $N$-hydroxysuccinimide ester; the aromatic part noncovalently attached on SWNT via $\pi-\pi$ interactions. SWCNs with a median length of $600 \mathrm{~nm}$ are able to display 26 molecules per particle, utilizing $80 \%$ available space. These TRAIL delivery systems demonstrated a 10-25-fold increase in efficacy in a wide variety of cell lines, including leukemic, lymphoma, non-small cell lung cancer, or hepatocarcinomas in vitro. ${ }^{18,24,48}$ Nevertheless, only a few NPs displaying TRAIL were evaluated in vivo: TRAIL/liposome systems have been shown to increase their pharmacodynamic profiles and inhibit tumor growth by $65 \%$ via i.p. injection every 2 days in the COLO205 human colorectal carcinoma cells xenograft model. ${ }^{51}$ Ferritin-displayed trimeric TRAIL well 
suppressed tumor growth, resulting in a $80.5 \%$ smaller tumor volume compared to buffer-treated ones in the HepG2 human hepatocellular carcinoma model. ${ }^{50}$ To date, there are no in vivo studies for elongated nanostructures. $13,52,53$

The reported PVX-based nanostructure displaying TRAIL offers advantages over previously explored systems: Data indicate that high aspect ratio materials are more beneficial for tumor drug delivery compared to spherical nanomaterials. To date, only one such system has been described in the context of TRAIL delivery, that is, using SWCNs. However, drawbacks are the biosafety profiles of carbon-based materials and their long residence time in the body (months). ${ }^{52}$ The proteinaceous PVX platform offers a higher degree of biosafety, because the particles are readily biodegradable and cleared from tissues within days. ${ }^{54}$

A further attributes of the PVX-TRAIL system are the easy molecular farming to produce batches of filamentous particles with a high degree of monodispersity and simple TRAIL loading procedures that do not require chemical alteration of the therapeutic protein TRAIL, ensuring its native structure for bioactivity as well as providing orientational control by coupling via its $\mathrm{N}$-terminus. With PVX, we achieved TRAIL loading to PVX with up to 490 TRAIL per PVX. This is the same loading efficiency of our previous work for PVX displaying fluorescent proteins ${ }^{30}$ and higher in loading capacity compared to other systems. ${ }^{24,48}$ Considering the curvature differences in sphere $v s$ rod when in contact with cancer cells, we hypothesize that our system would have enhanced crosslinking ability with receptors and thus effectively induce high levels of activated caspases signaling apoptosis. While HisTRAIL heterogeneity (monomers vs multimers) could be a concern, recent work indicates that multivalent presentation of surface-bound TRAIL, even in its monomeric form, efficiently induced clustering of death receptors leading to apoptosis. ${ }^{24}$ In addition, multimerization was also enhanced for His-TRAIL bound on NP carriers. ${ }^{54}$ In either scenarios, enhances in in vitro and in vivo efficacies were both observed; this could also be the case in our system, as a NTA group for TRAIL binding was linked to PVX by a flexible PEG linker, and this could favor the orientation of the therapeutic protein. $^{24,40}$ Our therapeutic system has shown a 10-fold increase in treatment efficacy $v s$ free drugs in a panel of TNBC cell lines in vitro; this is comparable with other described systems. $^{18,24,48}$ Furthermore, we demonstrate the use of elongated delivery system in the in vivo animal model bearing MDA-MB-231 TNBC cell lines; PVX-bound TRAIL, when intratumorally injected at the same dose, outperforms free TRAIL in delaying growth of tumor volumes. This study is a step toward bringing the TRAIL-based therapy, using elongated NPs for presenting and delivering, toward translational evaluations. A future direction would be developing genetic fusion techniques to incorporate TRAIL into PVX. This would streamline manufacturing (avoiding post-harvest modifications) and mitigate potential toxicity from the Ni used for complexation of His-tagged TRAIL.

\section{CONCLUSIONS}

In conclusion, we demonstrate the use of PVX, a naturally occurring nanoplatform with a flexuous filamentous structure for TRAIL presentation and delivery, mimicking bioactive membrane-bound TRAIL. When tested in a panel of TNBC cell lines, PVX-HisTRAIL shows 3-10-fold enhanced cellkilling effects to HisTRAIL alone in vitro. The conjugate also effectively inhibited tumor growth in an athymic nude mouse model of TNBC when injected intratumorally. In this study, we focused on intratumoral treatment to dissect the differences of efficacy comparing free $v s$ PVX-displayed TRAIL given at the same dosage. In addition, not only limited in monotherapies, two-pronged therapeutic strategies could be also developed, for example, PVX could display TRAIL and/or additional targeting ligands while loading doxorubicin within the grooves ${ }^{27}$ for synergetic effects in killing cancer, especially in drug-resistant cell lines. Overall, this work not only highlights the potentials of filamentous PVX for TRAILbased therapy but also provides valuable design guidelines for developing therapeutic NPs, especially ones with high aspect ratios, for clinical applications.

\section{EXPERIMENTAL SECTION}

Preparation of PVX Displaying Nickel-Coordinated Nitrilotriacetic Acid (PVX-Ni). PVX was propagated in Nicotiana benthamiana plants and purified according to our established protocol. $^{28}$ About $20 \mathrm{mg}$ of PVX particles were obtained from 100 $\mathrm{g}$ infected leaves. We developed a conjugation method to display $\mathrm{Ni}$ NTA as described in Figure S1. Briefly, PVX was first modified to display azido groups $\left(\mathrm{PVX}_{3}-\mathrm{N}_{3}\right)$, followed by the $\mathrm{Cu}(\mathrm{I})$-catalyzed azide-alkyne cycloaddition (CuCAAC, "click" chemistry) reaction to introduce the nitrilotriacetic (NTA) group. PVX displaying NTA (PVX-NTA) was dialyzed against PBS, pH 7.4 containing $1 \mathrm{mM} \mathrm{Ni}{ }^{2+}$ overnight at room temperature to obtain PVX displaying Ni-NTA (PVX-Ni). The concentrations of PVX and its derivatives (PVX-N $\mathrm{N}_{3}$, PVX-NTA, PVX-Ni) were determined from the absorbance at 260 $\mathrm{nm}$, read on a Nanodrop $2000 \mathrm{UV}$-vis spectrometer (Thermo Fisher), and calculated using the Beer-Lambert law and PVX-specific extinction coefficient $\left(2.97 \mathrm{~mL} \mathrm{mg}^{-1} \mathrm{~cm}^{-1}\right.$ at $\left.260 \mathrm{~nm}\right)$. To confirm the presence of $\mathrm{Ni}^{2+}$ in the PVX-Ni formulation, PVX-Ni $(2 \mathrm{mg}$ $\mathrm{mL}^{-1}$ ) was treated with DTT (Gold Biotechnology) at a $100 \mathrm{mM}$ final concentration; presence of $\mathrm{Ni}^{2+}$ is indicated by the solution turning into a yellow-brownish color, which is indicative of the reduction of $\mathrm{Ni}^{2+}$ ions (Figure S2).

Plasmid Construction, Protein Expression, and Purification of HisTRAIL. A gene encoding the C-terminal extracellular region (aa 114-281) of TRAIL, flanked with NdeI and SacI restriction enzyme sites at the $5^{\prime}$ and $3^{\prime}$ ends, respectively, was synthesized by Integrated DNA Technologies (IDT). The gene fragment was excised by double digestion using the enzymes NdeI and SacI (New England Biolabs, NEB) and inserted into pET-28a(+) vector (a kind gift from Dr. Ljerka Kunst, the University of British Columbia) at the corresponding sites to yield pET-28a(+)/HisTRAIL, which was subsequently transformed into Clear Coli BL21DE3 (Lucigen) for expression. The expressed protein has an $\mathrm{N}$-terminal His-tag, followed by a thrombin cleavage sequence allowing for removal of the His-tag if desired and a C-terminal bioactive human TRAIL (aa 114-281), denoted as HisTRAIL (Figure S3A). Clear Coli BL21DE3 were inoculated in TB culture for TRAIL expression, followed by the purification using metal-affinity chromatography. Purified HisTRAIL was confirmed by denaturing gel electrophoresis (SDS-PAGE) and Western blot analysis (Figure S3B). Details of TRAIL expression, purification, and characterization are described in Supporting Information. The protein concentration was measured using a Nanodrop 2000 UV-vis spectrometer. The extinction coefficient of HisTRAIL was calculated as $27,390 \mathrm{M}^{-1} \mathrm{~cm}^{-1}$ at $280 \mathrm{~nm}$, using the ProtParam tool (https://web.expasy.org/protparam/) based on the number of tryptophan, tyrosine, and cysteine.

Size Exclusion Chromatography (SEC). The particles (PVX-Ni or PVX-HisTRAIL-Cy5) or the protein (HisTRAIL-Cy5) in PBS, pH 7.4 were analyzed by SEC using a Superose- 6 column on the ÄKTA Explorer chromatography system (GE Healthcare). The flow rate was set at $0.5 \mathrm{~mL} \mathrm{~min}{ }^{-1}$. For detection of fluorescent molecules or macromolecules, the absorbances at $260 \mathrm{~nm}$ (RNA), $280 \mathrm{~nm}$ (protein), and $647 \mathrm{~nm}(\mathrm{Cy} 5)$ were recorded. 
Agarose Gel Electrophoresis. A $0.8 \%(w / v)$ agarose gel in TBE buffer was prepared for gel electrophoresis. Samples ( $5 \mu \mathrm{g}$ PVX-Ni or PVX-HisTRAIL-Cy5 and $1 \mu \mathrm{g}$ HisTRAIL-Cy5) were loaded and run at $100 \mathrm{~V}$ for $40 \mathrm{~min}$ in TBE buffer. Gels were imaged using a FluorChem R system instrument (ProteinSimple) upon excitation at $632 \mathrm{~nm}$ (red) for detection of the fluorescently labeled protein or particle. Gels were then stained with $\mathrm{CB}$ and imaged under white light using a FluorChem R system instrument.

Transmission Electron Microscopy (TEM) and Immunogold Staining. TEM was used to confirm the filamentous structure of PVX-HisTRAIL-biotin. In addition, immunostaining was performed to further confirm that indeed biotinylated HisTRAIL was present on PVX (PVX-HisTRAIL-biotin). PVX-HisTRAIL-biotin $\left(0.1 \mathrm{mg} \mathrm{mL}^{-1}\right)$ and PVX-Ni $\left(0.1 \mathrm{mg} \mathrm{mL}^{-1}\right)$, the latter served as the negative control, were loaded onto carbon-coated copper grids, followed by fixation in $2.5 \%(\mathrm{v} / \mathrm{v})$ glutaraldehyde solution for $10 \mathrm{~min}$ at room temperature. The grids were then washed with PBS, pH 7.4 and then blocked using $1 \%(\mathrm{w} / \mathrm{v})$ bovine serum albumin (BSA) in PBS, $\mathrm{pH} 7.4$ containing $0.1 \%(\mathrm{v} / \mathrm{v})$ Tween 20 for $30 \mathrm{~min}$. Samples were equilibrated with $0.1 \%(\mathrm{w} / \mathrm{v}) \mathrm{BSA}$ for $5 \mathrm{~min}$ and then stained with $10 \mathrm{~nm}$ gold NPs conjugated with antibiotin antibodies (AURION) diluted 5 times in $\mathrm{PBS}, \mathrm{pH}$ 7.4. All samples were negative-stained using $2 \%(\mathrm{w} / \mathrm{v})$ uranyl acetate for $1 \mathrm{~min}$ prior to TEM imaging. TEM imaging was conducted using an FEI Tecnai F30 transmission electron microscope operated at $300 \mathrm{kV}$.

Denaturing Gel Electrophoresis, SDS-PAGE, and Fluorescent Western Blot (WB) for TRAIL Quantitative Analysis. Denatured protein samples $(5 \mu \mathrm{g})$ in the presence of reducing reagent DTT were loaded on a 4-12\% NuPAGE gel (Life Technologies) in 1 $\times$ MOPS running buffer. The electrophoresis was conducted at a constant voltage $(200 \mathrm{~V})$ for $35 \mathrm{~min}$. Protein bands were visualized under white light after $\mathrm{CB}$ staining by FluoroChem $\mathrm{R}$ imaging instrument. Band thickness analyses were analyzed by ImageJ $1.47 \mathrm{~d}$ (http://imagej.nih.gov/ij) to determine the weight ratio between HisTRAIL and PVX CP.

For WB, PVX-HisTRAIL was loaded with $10 \mu \mathrm{L}$ suspension at 1.0 $\mathrm{mg} \mathrm{mL} L^{-1}$ or $10 \times$ dilution under denaturing condition with DTT. This concentration range was within the linear detection range of a standard curve which was established using PVX and HisTRAIL at defined and known concentrations. Protein concentrations were determined by Bradford assay kit (Biorad). For the PVX standard curve, $0.1,0.25,0.5,1 \mu \mathrm{g}$ particles were loaded. For HisTRAIL standard curve, the protein was loaded at $0.25,0.5,1,2.5$, and $5 \mu \mathrm{g}$. After separation of PVX-HisTRAIL and controls by SDS-PAGE, the proteins were transferred onto a nitrocellulose membrane (Thermo Scientific) using NuPAGE transfer buffer (Invitrogen). Blocking was conducted in $0.1 \mathrm{M}$ Tris-buffered saline (TBS, pH 7.6) containing $5 \%$ $(\mathrm{w} / \mathrm{v})$ milk and $0.05 \%(\mathrm{v} / \mathrm{v})$ Tween 20. PVX and HisTRAIL were detected using a rabbit anti-PVX antibody (Pacific Immunology) and a rabbit anti-TRAIL primary antibody (Biovision), followed by detection from anti-rabbit secondary antibody conjugated with IRDye $800 \mathrm{CW}(774 / 789 \mathrm{~nm})$ (LICOR). The membrane was visualized under infrared light; the fluorescence intensities were determined by FluoroChem $\mathrm{R}$ imaging instrument.

Cell Culture. Triple-negative breast cancer (TNBC) MDA-MB231, HCC-38, and BT-549 cell lines as well as the HER-2 amplified breast cancer, SK-BR-3 cell line were purchased from ATCC. MDAMB-231, HCC-38, BT-549, and SK-BR-3 were cultured in Dulbecco's modified Eagle's medium (DMEM), Roswell Park Memorial Institute (RPMI) 1640 medium without or with insulin $(0.023 \mathrm{IU} / \mathrm{mL}$ final concentration), and McCoy's 5A medium, respectively. All media were supplemented with $10 \%(\mathrm{v} / \mathrm{v})$ FBS and $1 \%(\mathrm{v} / \mathrm{v})$ penicillin/ streptomycin. All cells were maintained at $37{ }^{\circ} \mathrm{C}$ and $5 \% \mathrm{CO}_{2}$.

MTT Cytotoxicity Assays. Cells (MDA-MB-231, HCC-38, BT549, and SK-BR-3) were seeded at 5000 cells per well in the corresponding culture medium in 96-well plates 1 day prior to treatment. The next day, cells were treated with HisTRAIL or PVXHisTRAIL at $1,5,10,25,50,100,250,500 \mathrm{ng} \mathrm{mL}^{-1}$ normalized to HisTRAIL for $12 \mathrm{~h}$ in medium at $37{ }^{\circ} \mathrm{C}$ and $5 \% \mathrm{CO}_{2}$. Samples were prepared in triplicate, and each assay was performed at least twice.
PVX-Ni was added at the particle concentration matching the highest dose of PVX-HisTRAIL as a control to assess carrier toxicity (or lack thereof). Following incubation, cells were washed with PBS, pH 7.4, and fresh medium was replenished, and then $10 \mu \mathrm{L}$ MTT reagent was added as per manufacturer's instructions. Absorbance was determined using the Tecan infinite-M200 plate reader.

Determination of Levels of Activated Caspase-8 and Caspase-3/7. MDA-MB-231 cells were seeded at 5000 cells per well in a white-walled 96-well luminometer microplate 1 day prior to treatment. The next day, medium was exchanged with DMEM medium containing HisTRAIL or PVX-HisTRAIL $\left(20 \mathrm{ng} \mathrm{mL}^{-1}\right)$; treatment was allowed to proceed for $3 \mathrm{~h}$. Nontreated cells were used as control. Samples were prepared in triplicate. Caspase-Glo 8 assay kit and Caspase-Glo 3/7 assay kit (Promega) were used to determine the level of activated caspases upon HisTRAIL or PVX-HisTRAIL treatment. Briefly, the reagent causes cell lysis, followed by caspase cleavage of the substrate and aminoluciferin which produces a luminescent signal in the presence of luciferase and ATP from the kit. Luminescence was read by the Tecan infinite-M200 plate reader to determine the proportional activated level of caspase- 8 and caspase-3/ 7.

In Vivo Treatment Efficacy Using the MDA-MB-231 Model. The animal study was carried under a Case Western Reserve University IACUC-approved protocol. Female NCR nu/nu mice (68 weeks old) were injected subcutaneously into the right flank with 2 $\times 10^{6}$ cells suspended in $100 \mu \mathrm{L}$ of media and Matrigel (Corning) at a 1:1 ratio. Treatment was started when tumor volume reached 100$150 \mathrm{~mm}^{3}$. Mice were randomly assigned to groups including PBS- $(n$ $=4)$, PVX-Ni- $(n=4)$, HisTRAIL- $(n=5)$, and PVX-HisTRAILtreated groups $(n=6)$. Freshly prepared HisTRAIL or PVXHisTRAIL was injected intratumorally at a dose of $5 \mu \mathrm{L}$ therapeutic protein per injection. PBS and PVX-Ni, at the corresponding content of particle in the conjugate, were used as controls. Tumors were measured daily, and the volume was calculated using the formula $v=$ $\left(l \times w^{2}\right) / 2$, where $l$ is the length and $w$ is the width of tumor. Mice were also weighted to monitor potential side effects. All mice were euthanized, and tumors were collected at the end of the study for imaging. All results are expressed as means $\pm S D$, calculated by GraphPad Prism. Statistical comparisons were made using one-way ANOVA. Differences between each group were considered significant at $P$ value $<0.05$.

\section{ASSOCIATED CONTENT}

\section{Supporting Information}

The Supporting Information is available free of charge on the ACS Publications website at DOI: 10.1021/acsnano.8b09462.

Bioconjugation procedures for preparing PVX-Ni (Figures S1 and S2), expression, purification, and characterization of HisTRAIL (Figure S3), fluorescent labeling of HisTRAIL with Cy5 (Figure S4), SEC profile of PVX (Figure S5), biotinylation of HisTRAIL and characterization (Figure S6), SEC profile of PVXHisTRAIL conjugate (Figure S7), MTT assay for treatment efficacy in SK-BR-3 (Figure S8), body weight measurement of treated mice (Figure S9) (PDF)

\section{AUTHOR INFORMATION}

\section{Corresponding Author}

*E-mail: nsteinmetz@ucsd.edu.

ORCID $\odot$

Duc H. T. Le: 0000-0002-3539-0462

Nicole F. Steinmetz: 0000-0002-0130-0481

\section{Present Address}

"Eindhoven University of Technology, P.O. Box 513 (STO 3.25), 5600MB Eindhoven, The Netherlands; Department of 
Biochemistry, Radboudumc, Geert Grooteplein 28, 6525 GA Nijmegen, The Netherlands.

\section{Notes}

The authors declare no competing financial interest.

\section{ACKNOWLEDGMENTS}

This work was supported by a Research Scholar Award from the American Cancer Society (128319-RSG-15-144-01-CDD).

\section{REFERENCES}

(1) Wong, R. S. Apoptosis in Cancer: From Pathogenesis to Treatment. J. Exp. Clin. Cancer Res. 2011, 30, 87.

(2) Takeda, K.; Hayakawa, Y.; Smyth, M. J.; Kayagaki, N.; Yamaguchi, N.; Kakuta, S.; Iwakura, Y.; Yagita, H.; Okumura, K. Involvement of Tumor Necrosis Factor-Related Apoptosis-Inducing Ligand in Surveillance of Tumor Metastasis by Liver Natural Killer Cells. Nat. Med. 2001, 7, 94-100.

(3) Yang, A.; Wilson, N. S.; Ashkenazi, A. Proapoptotic DR4 and DR5 Signaling in Cancer Cells: Toward Clinical Translation. Curr. Opin. Cell Biol. 2010, 22, 837-844.

(4) Johnstone, R. W.; Frew, A. J.; Smyth, M. J. The TRAIL Apoptotic Pathway in Cancer Onset, Progression and Therapy. Nat. Rev. Cancer 2008, 8, 782-798.

(5) LeBlanc, H. N.; Ashkenazi, A. Apo2L/TRAIL and Its Death and Decoy Receptors. Cell Death Differ. 2003, 10, 66-75.

(6) Schneider, B.; Munkel, S.; Krippner-Heidenreich, A.; Grunwald, I.; Wels, W. S.; Wajant, H.; Pfizenmaier, K.; Gerspach, J. Potent Antitumoral Activity of TRAIL through Generation of TumorTargeted Single-Chain Fusion Proteins. Cell Death Dis. 2010, 1, e68.

(7) Stuckey, D. W.; Shah, K. TRAIL on Trial: Preclinical Advances in Cancer Therapy. Trends Mol. Med. 2013, 19, 685-694.

(8) Herbst, R. S.; Eckhardt, S. G.; Kurzrock, R.; Ebbinghaus, S.; O'Dwyer, P. J.; Gordon, M. S.; Novotny, W.; Goldwasser, M. A.; Tohnya, T. M.; Lum, B. L.; Ashkenazi, A.; Jubb, A. M.; Mendelson, D. S. Phase I Dose-Escalation Study of Recombinant Human Apo2L/ TRAIL, a Dual Proapoptotic Receptor Agonist, in Patients with Advanced Cancer. J. Clin. Oncol. 2010, 28, 2839-2846.

(9) Subbiah, V.; Brown, R. E.; Buryanek, J.; Trent, J.; Ashkenazi, A.; Herbst, R.; Kurzrock, R. Targeting the Apoptotic Pathway in Chondrosarcoma Using Recombinant Human Apo2L/TRAIL (Dulanermin), a Dual Proapoptotic Receptor (DR4/DR5) Agonist. Mol. Cancer Ther. 2012, 11, 2541-2546.

(10) Ashkenazi, A. Targeting the Extrinsic Apoptotic Pathway in Cancer: Lessons Learned and Future Directions. J. Clin. Invest. 2015, 125, 487-489.

(11) Sun, T.; Zhang, Y. S.; Pang, B.; Hyun, D. C.; Yang, M.; Xia, Y. Engineered Nanoparticles for Drug Delivery in Cancer Therapy. Angew. Chem., Int. Ed. 2014, 53, 12320-12364.

(12) Belkahla, H.; Herlem, G.; Picaud, F.; Gharbi, T.; Hemadi, M.; Ammar, S.; Micheau, O. TRAIL-NP Hybrids for Cancer Therapy: A Review. Nanoscale 2017, 9, 5755-5768.

(13) Guimarães, P. P. G.; Gaglione, S.; Sewastianik, T.; Carrasco, R. D.; Langer, R.; Mitchell, M. J. Nanoparticles for Immune Cytokine TRAIL-Based Cancer Therapy. ACS Nano 2018, 12, 912-931.

(14) De Miguel, D.; Gallego-Lleyda, A.; Anel, A.; Martinez-Lostao, L. Liposome-Bound TRAIL Induces Superior DR5 Clustering and Enhanced Disc Recruitment in Histiocytic Lymphoma U937 Cells. Leuk. Res. 2015, 39, 657-666.

(15) Kim, T. H.; Jo, Y. G.; Jiang, H. H.; Lim, S. M.; Youn, Y. S.; Lee, S.; Chen, X.; Byun, Y.; Lee, K. C. PEG-Transferrin Conjugated TRAIL (TNF-Related Apoptosis-Inducing Ligand) for Therapeutic Tumor Targeting. J. Controlled Release 2012, 162, 422-428.

(16) Thao, L. Q.; Byeon, H. J.; Lee, C.; Lee, S.; Lee, E. S.; Choi, Y. W.; Choi, H. G.; Park, E. S.; Lee, K. C.; Youn, Y. S. DoxorubicinBound Albumin Nanoparticles Containing a TRAIL Protein for Targeted Treatment of Colon Cancer. Pharm. Res. 2016, 33, 615626.
(17) Cho, M. H.; Lee, E. J.; Son, M.; Lee, J. H.; Yoo, D.; Kim, J. W.; Park, S. W.; Shin, J. S.; Cheon, J. A Magnetic Switch for the Control of Cell Death Signalling in in Vitro and in Vivo Systems. Nat. Mater. 2012, 11, 1038-1043.

(18) Seifert, O.; Pollak, N.; Nusser, A.; Steiniger, F.; Ruger, R.; Pfizenmaier, K.; Kontermann, R. E. Immuno-LipoTRAIL: Targeted Delivery of TRAIL-Functionalized Liposomal Nanoparticles. Bioconjugate Chem. 2014, 25, 879-887.

(19) Blanco, E.; Shen, H.; Ferrari, M. Principles of Nanoparticle Design for Overcoming Biological Barriers to Drug Delivery. Nat. Biotechnol. 2015, 33, 941-951.

(20) Kinnear, C.; Moore, T. L.; Rodriguez-Lorenzo, L.; RothenRutishauser, B.; Petri-Fink, A. Form Follows Function: Nanoparticle Shape and Its Implications for Nanomedicine. Chem. Rev. 2017, 117, 11476-11521.

(21) Xu, J.; Wong, D. H.; Byrne, J. D.; Chen, K.; Bowerman, C.; DeSimone, J. M. Future of the Particle Replication in Nonwetting Templates (PRINT) Technology. Angew. Chem., Int. Ed. 2013, 52, $6580-6589$.

(22) Liu, Z.; Robinson, J. T.; Tabakman, S. M.; Yang, K.; Dai, H. J. Carbon Materials for Drug Delivery \& Cancer Therapy. Mater. Today 2011, 14, 316-323.

(23) Jelonek, K.; Li, S.; Wu, X.; Kasperczyk, J.; Marcinkowski, A. Self-Assembled Filomicelles Prepared from Polylactide/Poly(Ethylene Glycol) Block Copolymers for Anticancer Drug Delivery. Int. J. Pharm. 2015, 485, 357-364.

(24) Zakaria, A. B.; Picaud, F.; Rattier, T.; Pudlo, M.; Dufour, F.; Saviot, L.; Chassagnon, R.; Lherminier, J.; Gharbi, T.; Micheau, O.; Herlem, G. Nanovectorization of TRAIL with Single Wall Carbon Nanotubes Enhances Tumor Cell Killing. Nano Lett. 2015, 15, 891895.

(25) Czapar, A. E.; Zheng, Y. R.; Riddell, I. A.; Shukla, S.; Awuah, S. G.; Lippard, S. J.; Steinmetz, N. F. Tobacco Mosaic Virus Delivery of Phenanthriplatin for Cancer Therapy. ACS Nano 2016, 10, 41194126.

(26) Franke, C. E.; Czapar, A. E.; Patel, R. B.; Steinmetz, N. F. Tobacco Mosaic Virus-Delivered Cisplatin Restores Efficacy in Platinum-Resistant Ovarian Cancer Cells. Mol. Pharmaceutics 2018, 15, 2922-2931.

(27) Le, D. H.; Lee, K. L.; Shukla, S.; Commandeur, U.; Steinmetz, N. F. Potato Virus X, a Filamentous Plant Viral Nanoparticle for Doxorubicin Delivery in Cancer Therapy. Nanoscale 2017, 9, 23482357.

(28) Lee, K. L.; Uhde-Holzem, K.; Fischer, R.; Commandeur, U.; Steinmetz, N. F. Genetic Engineering and Chemical Conjugation of Potato Virus X. Methods Mol. Biol. 2014, 1108, 3-21.

(29) Blandino, A.; Lico, C.; Baschieri, S.; Barberini, L.; Cirotto, C.; Blasi, P.; Santi, L. In Vitro and in Vivo Toxicity Evaluation of Plant Virus Nanocarriers. Colloids Surf., B 2015, 129, 130-136.

(30) Le, D. H. T.; Hu, H.; Commandeur, U.; Steinmetz, N. F. Chemical Addressability of Potato Virus X for Its Applications in Bio/ Nanotechnology. J. Struct. Biol. 2017, 200, 360-368.

(31) Shukla, S.; Myers, J. T.; Woods, S. E.; Gong, X.; Czapar, A. E.; Commandeur, U.; Huang, A. Y.; Levine, A. D.; Steinmetz, N. F. Plant Viral Nanoparticles-Based HER2 Vaccine: Immune Response Influenced by Differential Transport, Localization and Cellular Interactions of Particulate Carriers. Biomaterials 2017, 121, 15-27.

(32) Lee, K. L.; Murray, A. A.; Le, D. H. T.; Sheen, M. R.; Shukla, S.; Commandeur, U.; Fiering, S.; Steinmetz, N. F. Combination of Plant Virus Nanoparticle-Based in Situ Vaccination with Chemotherapy Potentiates Antitumor Response. Nano Lett. 2017, 17, 4019-4028.

(33) Chariou, P. L.; Lee, K. L.; Wen, A. M.; Gulati, N. M.; Stewart, P. L.; Steinmetz, N. F. Detection and Imaging of Aggressive Cancer Cells Using an Epidermal Growth Factor Receptor (EGFR)-Targeted Filamentous Plant Virus-Based Nanoparticle. Bioconjugate Chem. 2015, 26, 262-269.

(34) Shukla, S.; Dickmeis, C.; Nagarajan, A. S.; Fischer, R.; Commandeur, U.; Steinmetz, N. F. Molecular Farming of Fluorescent 
Virus-Based Nanoparticles for Optical Imaging in Plants, Human Cells and Mouse Models. Biomater. Sci. 2014, 2, 784-797.

(35) Steinmetz, N. F.; Mertens, M. E.; Taurog, R. E.; Johnson, J. E.; Commandeur, U.; Fischer, R.; Manchester, M. Potato Virus X as a Novel Platform for Potential Biomedical Applications. Nano Lett. 2010, 10, 305-312.

(36) Gulati, N. M.; Pitek, A. S.; Czapar, A. E.; Stewart, P. L.; Steinmetz, N. F. The in Vivo Fates of Plant Viral Nanoparticles Camouflaged Using Self-Proteins: Overcoming Immune Recognition. J. Mater. Chem. B 2018, 6, 2204-2216.

(37) Pitek, A. S.; Wang, Y.; Gulati, S.; Gao, H.; Stewart, P. L.; Simon, D. I.; Steinmetz, N. F. Elongated Plant Virus-Based Nanoparticles for Enhanced Delivery of Thrombolytic Therapies. Mol. Pharmaceutics 2017, 14, 3815-3823.

(38) Kim, T. H.; Swierczewska, M.; Oh, Y.; Kim, A.; Jo, D. G.; Park, J. H.; Byun, Y.; Sadegh-Nasseri, S.; Pomper, M. G.; Lee, K. C.; Lee, S. Mix to Validate: A Facile, Reversible PEGylation for Fast Screening of Potential Therapeutic Proteins in Vivo. Angew. Chem., Int. Ed. 2013, $52,6880-6884$.

(39) Lawrence, D.; Shahrokh, Z.; Marsters, S.; Achilles, K.; Shih, D.; Mounho, B.; Hillan, K.; Totpal, K.; DeForge, L.; Schow, P.; Hooley, J.; Sherwood, S.; Pai, R.; Leung, S.; Khan, L.; Gliniak, B.; Bussiere, J.; Smith, C. A.; Strom, S. S.; Kelley, S.; et al. Differential Hepatocyte Toxicity of Recombinant Apo2L/TRAIL Versions. Nat. Med. 2001, 7, $383-385$.

(40) De Miguel, D.; Gallego-Lleyda, A.; Ayuso, J. M.; PejenauteOchoa, D.; Jarauta, V.; Marzo, I.; Fernández, L. J.; Ochoa, I.; Conde, B.; Anel, A.; Martinez-Lostao, L. High-order TRAIL Oligomer Formation in TRAIL-Coated Lipid Nanoparticles Enhances DR5 Cross-Linking and Increases Antitumour Effect Against Colon Cancer. Cancer Lett. 2016, 383, 250-260.

(41) Rahman, M.; Pumphrey, J. G.; Lipkowitz, S. The TRAIL to Targeted Therapy of Breast Cancer. Adv. Cancer Res. 2009, 103, 4373.

(42) Rahman, M.; Davis, S. R.; Pumphrey, J. G.; Bao, J.; Nau, M. M.; Meltzer, P. S.; Lipkowitz, S. TRAIL Induces Apoptosis in TripleNegative Breast Cancer Cells with a Mesenchymal Phenotype. Breast Cancer Res. Treat. 2009, 113, 217-230.

(43) Wilhelm, S.; Tavares, A. J.; Dai, Q.; Ohta, S.; Audet, J.; Dvorak, H. F.; Chan, W. C. W. Analysis of Nanoparticle Delivery to Tumours. Nat. Rev. Mater. 2016, 1, 1-12.

(44) Park, K. Facing the Truth About Nanotechnology in Drug Delivery. ACS Nano 2013, 7, 7442-7447.

(45) Denkhaus, E.; Salnikow, K. Nickel Essentiality, Toxicity, and Carcinogenicity. Crit. Rev. Oncol. Hematol. 2002, 42, 35-56.

(46) Wang, S.; Ren, W.; Liu, J.; Lahat, G.; Torres, K.; Lopez, G.; Lazar, A. J.; Hayes-Jordan, A.; Liu, K.; Bankson, J.; Hazle, J. D.; Lev, D. TRAIL and Doxorubicin Combination Induces Proapoptotic and Antiangiogenic Effects in Soft Tissue Sarcoma in Vivo. Clin. Cancer Res. 2010, 16, 2591-2604.

(47) Mitchell, M. J.; Webster, J.; Chung, A.; Guimarães, P. P.; Khan, O. F.; Langer, R. Polymeric Mechanical Amplifiers of Immune Cytokine-Mediated Apoptosis. Nat. Commun. 2017, 8, 14179.

(48) De Miguel, D.; Basanez, G.; Sanchez, D.; Malo, P. G.; Marzo, I.; Larrad, L.; Naval, J.; Pardo, J.; Anel, A.; Martinez-Lostao, L. Liposomes Decorated with Apo2L/TRAIL Overcome Chemoresistance of Human Hematologic Tumor Cells. Mol. Pharmaceutics 2013, 10, 893-904.

(49) Mitchell, M. J.; Wayne, E.; Rana, K.; Schaffer, C. B.; King, M. R. TRAIL-Coated Leukocytes That Kill Cancer Cells in the Circulation. Proc. Natl. Acad. Sci. U. S. A. 2014, 111, 930-935.

(50) Kih, M.; Lee, E. J.; Lee, N. K.; Kim, Y. K.; Lee, K. E.; Jeong, C.; Yang, Y.; Kim, D. H.; Kim, I. S. Designed Trimer-Mimetic TNF Superfamily Ligands on Self-Assembling Nanocages. Biomaterials 2018, 180, 67-77.

(51) Nair, P. M.; Flores, H.; Gogineni, A.; Marsters, S.; Lawrence, D. A.; Kelley, R. F.; Ngu, H.; Sagolla, M.; Komuves, L.; Bourgon, R.; Settleman, J.; Ashkenazi, A. Enhancing the Antitumor Efficacy of a
Cell-Surface Death Ligand by Covalent Membrane Display. Proc. Natl. Acad. Sci. U. S. A. 2015, 112, 5679-5684.

(52) de Miguel, D.; Lemke, J.; Anel, A.; Walczak, H.; MartinezLostao, L. Onto Better TRAILs for Cancer Treatment. Cell Death Differ. 2016, 23, 733-747.

(53) Liu, Z.; Davis, C.; Cai, W.; He, L.; Chen, X.; Dai, H. Circulation and Long-Term Fate of Functionalized, Biocompatible Single-Walled Carbon Nanotubes in Mice Probed by Raman Spectroscopy. Proc. Natl. Acad. Sci. U. S. A. 2008, 105, 1410-1415.

(54) Lee, K. L.; Shukla, S.; Wu, M.; Ayat, N. R.; El Sanadi, C. E.; Wen, A. M.; Edelbrock, J. F.; Pokorski, J. K.; Commandeur, U.; Dubyak, G. R.; Steinmetz, N. F. Stealth Filaments: Polymer Chain Length and Conformation Affect the in Vivo Fate of PEGylated Potato Virus X. Acta Biomater. 2015, 19, 166-179. 